\title{
O QUE A HOMOSSEXUALIDADE INDÍGENA PODE ENSINAR SOBRE COLONIALISMO - E COMO RESISTIR A ELE ${ }^{1}$
}

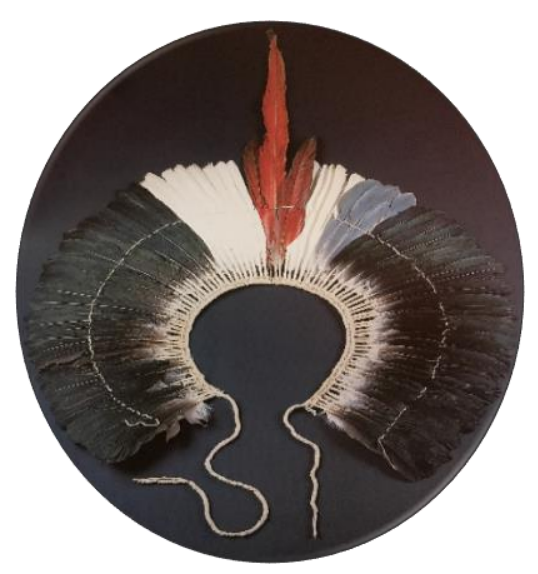

Estevão Rafael Fernandes ${ }^{2}$

RESUMO: Este texto pretende apontar, a partir de questões relacionadas ao estudo da homossexualidade indígena, questões referentes à colonização e aos desafios a este tipo de estudo dentro de uma academia colonizada, epistemicamente. Nesse sentido, busca-se chamar a atenção para como a colonização consiste na formação de um aparato discursivo e institucional que busca, em última instância, anular a condição de existência de seus outros ontológicos.

PALAVRAS-CHAVE: Homossexualidade indígena. Colonialismo. Sexualidade.

\footnotetext{
${ }^{1}$ Parte deste artigo baseia-se em entrevista dada a Helô D'Angelo, para o sítio da revista Cult, resultando na reportagem "Estudo mostra diversidade de práticas sexuais entre indígenas no Brasil pré-colonial", publicada em 26 de junho de 2017, disponível em https://revistacult.uol.com.br/home/estudomostra-diversidade-de-praticas-sexuais-entre-indigenas-no-brasil-precolonial/

2 Antropólogo, Doutor em Ciências Sociais pela Universidade de Brasília (2015). Professor do Departamento de Ciências Sociais da Universidade Federal de Rondônia. E-mail estevaofernandes@gmail.com
} 
Há certas coisas que não entram no lattes. Há cerca de um ano e meio, Johannes Haushofer causou sensação ao fazer, nos Estados Unidos, uma espécie de anticurrículo, relacionando todos os seus fracassos, tais como bolsas não obtidas, projetos não aprovados e artigos não publicados. De fato, o ritmo de produção fordista imposto por agências de fomento, programas de pós-graduação ou mesmo pela insana - e inconsequente - egolatria acadêmica faze com que o lattes se torne uma espécie de ídolo a ser alimentado, um fetiche, um facebook acadêmico. De fato, quando nossa suada produção vira pixels na tela do lattes, não transparecem todos os transtornos, renúncias, problemas psicológicos, momentos de solidão, frustração, negação e agonia. O trabalho intelectual é uma viagem solitária para dentro de si, e não importa quão amável seja nossa família ou quão sensível sejam nossxs professorxs, orientadorxs ou colegas: o peso e a cobrança sobre nossos ombros são algo desumano e desumanizante. Poucas vezes nos questionamos sobre o que ocasionou essa estrutura de poderes para a qual somos tragados, talvez como um modo de nos dessensibilizarmos no processo. Afinal de contas, muitas vezes nos tornamos aquilo que jurávamos que nunca seríamos: um intelectual arrogante, narcisista, ensimesmado, crente em uma ciência objetiva, neutra e sem agência; na qual figuremos sem história, sem sexo, sem raça; na qual não cabem sotaques, angústias, subjetividades, afetos.

Talvez essa seja uma leitura equivocada e estejamos, no fim das contas, nos deixando anular por um conjunto de relações de poder que sejam, elas mesmas, parte de uma configuração mais ampla de anulação de um conjunto de vozes dissonantes, a partir das quais nos tornamos reativos, agentes de nós mesmos e de nossa própria voz, ativos frente à cálida vOz de um conjunto de saberes que gradualmente nos isola de nossas próprias experiências pessoais. A ciência, da forma como somos domesticados a pensa-la, torna-se gradualmente uma experiência de autoapagamento, autoisolamento, autoanulação ontológica. O que, gradualmente, deveria nos 
levar à ampliação de nosso lugar no mundo se torna um não-lugar, sendo as torres de marfim da academia hegemônica um objetivo em si mesmo.

Penso que tal conjunto de ideias mereça ser devidamente enfrentado, e sei que há gente mais capacitada que eu para falar dessas questões. Filósofos da ciência, epistemólogos, e tantas áreas acadêmicas se dedicam a estudar ou a criticar tal divisão de saberes. Mas a questão não é - ou pelo menos não somente - compreender as razões institucionais que levaram a esta ou aquela configuração específica de saberes (autores como Immanuel Wallerstein, Simon Schwartzman e Bruno Latour, por exemplo, cada um a seu modo, trabalha de modo bem interessante essas questões) mas, sobretudo, como enfrenta-las e por quê enfrenta-las. Não se trata apenas de se contrapor uma forma de conhecimento a partir da qual se desaprende a aprender (invertendo o título do livro de Mignolo e Tlostanova, Learning to unlearn), mas de contrapor os feixes discursivos e dispositivos intrínsecos a tal modo de se constituir conhecimento.

Saber e poder, como tão bem demonstraram Foucault e tantxs outrxs, são esferas estritamente relacionadas. Poucas vezes somos lembrados, nas ciências sociais, como nossos "pais fundadores" (aliás, onde estão as mães fundadoras?!) corroboraram teorias racistas, misóginas, colonizadoras, eugênicas,... A ciência que replicamos é hétero, misógina, patriarcal, masculinizante, liberal, euronorcêntrica, branca, de classe média e urbana e, em larga medida, se pauta no apagamento de saberes outros. Nossa epistemologia é um rolo compressor, enquanto parte de um sistema colonial de saberes e poderes, de apagamento de diversidades de pontos de vista, de subjetividades, de afetos, de vidas.

Particularmente - sim, pois este texto não é neutro, pois foi feito por um ser humano para outros seres humanos, todos devidamente investidos de suas histórias -; os textos que mais diretamente me impactaram foram escritos com a alma, em primeira pessoa. Uma escrita visceral, de gente para gente. É o que sinto quando leio Gloria Anzaldúa, falando de sua consciência 
mestiça; ou dos caminhos que levaram Frantz Fanon a sentir - note: sentir! - como o colonialismo é um processo de desumanização. São estas mesmas questões que me levam a pensar, por exemplo, por que não temos ainda, no Brasil, um conjunto articulado de estudos e autores que se percebam como críticos pós-coloniais, talvez por paranoicos que estejamos em citar o último autor francês da moda, ou aquela escritora americana de vanguarda.

Temos, no Brasil, autorxs negrxs, críticxs queer, pensadorxs indígenas, ribeirinhxs, quilombolas, sertanejxs, ribeirinhxs, camponesxs capazes de articularem, desde suas próprias experiências e vivências, uma crítica original dos processos que levaram a sua subalternização e apagamento. Onde estão que não são vistxs e ouvidxs? Não apenas lhes falta espaço nas cadeiras das universidades e centros de pesquisa, mas, de forma mais vil, nota-se sua ausência em bibliografias de curso, dossiês e coletâneas. Quais são os não ditos, no âmbito das ciências sociais e humanas do país? Quais são os nãoobjetos? Que cruzamentos de saberes, conceitos e perceptos poderiam ser feitos? Desde que lugares de interlocução tais atores poderiam estar articulando sua crítica anticolonial, expandindo nossos olhares para além dos campos já consolidados no âmbito das ciências constituídas? Quantxs autorxs lidxs em nossa formação nasceram em países abaixo do rio Grande? Quantxs não estão institucionalmente localizadxs em instituições centrais? Por que escrever "quantxs" incomoda tanto, pois naturalizamos "quantos", acadêmicos", "professores", etc., associando a construção desses espaços ao macho, ao masculino, ao homem. Não se trata, meramente, de uma preferência linguística - e quem insiste em chamar uma presidenta de presidente, sabe disso.

Indo mais além: onde está a vasta filosofia africana, os feminismos latinos, as críticas indígenas?... a lista de apagamentos de saberes é ampla, ao contrário dos paradigmas que temos disponíveis, tão bem constituídos em nossos departamentos e bibliotecas. Gradualmente, nos domesticamos, nos 
adequamos, nos deixamos levar pela retórica do distanciamento. Nos deixamos colonizar.

Desta forma, a partir de alguns dos meus percursos - intelectuais, afetivos, subjetivos - pretendo apontar, aqui, algumas questões que dizem respeito a questão do colonialismo, sobretudo se pensado desde um aspecto mais particular - dos processos de colonização das sexualidades indígenas.

A medida que traço esse conjunto de considerações, buscarei, também, apontar algumas das dificuldades enfrentadas até aqui. De certa forma, este texto acaba sendo um grande desabafo sobre questões que me angustiam e, espero, venham a motivar outras pessoas a pensa-las e enfrentalas. O colonialismo não apenas rouba terras, saberes, subjetividades: ele também tolhe solidariedades, redes, nos transforma em indivíduos à medida em que nos rouba a personitude, a agência. O colonialismo é meritocrático, individualista e liberal e, por isso mesmo, hipócrita. Desta forma, a única saída possível é acessar e desvelar as zonas obscuras criadas pela colonização, zonas não acessadas pela forma como o conhecimento historicamente se constitui no âmbito das ciências sociais hegemônicas.

Minha hipótese aqui, ainda que não seja tão original assim, é que a colonização não acabou, mas prossegue viva e forte, baseando-se em um tripé raça/classe/sexualidade. Sua parte mais visível são as práticas institucionais, mas um ponto a ser evidenciado nesses processos são os feixes discursivos que funcionam como aparato ideológico dessas práticas.

No tocante, especificamente, à colonização das sexualidades indígenas, isso significa que as políticas de miscigenação forçada, a imposição de nomes "de branco" aos indígenas, a divisão no trabalho e no espaço escolar, os cortes de cabelo, a distribuição de roupas e outras tantas ações nas quais historicamente a ação indigenista da sociedade envolvente se pauta/pautou são baseadas em - ao mesmo tempo em que sustentam - um sistema discursivo de sexualidade do colonizador. Desta forma, a vocação de um pensamento genuinamente crítico ao processo colonial precisa levar em 
conta tanto o processo colonizador, em si, quanto da nuvem discursiva que o legitimou e legitima.

Assim, a título de hipótese, apresentarei em seguida alguns pontos (em itálico, a seguir), que, de certa forma, sintetizam algumas questões referentes a relação entre o colonialismo e as sexualidades indígenas, de modo mais particular. Entretanto, parece importante indicar, aqui, que estes pontos dificilmente se restringem ao manejo das sexualidades indígenas: parece certo que este processo ocorre de forma muito mais ampla, alcançando todos os atores sujeitos à ação da máquina colonial, ainda que sob outras dialéticas. Dessa forma, se este texto parte das experiências indígenas, certamente negrxs, ribeirnhxs, sertanejxs, dentre outros, além mesmo de coletivos urbanos (especialmente nas periferias) sofreram e sofrem com as dinâmicas impostas pelos setores hegemônicos do colonialismo.

\section{A colonização são as práticas institucionais, mas também o conjunto de saberes por trás dessas práticas}

A colonização baseia-se em um conjunto de relações de poder que opera em relação a noções como raça, gênero e povo/nação, por exemplo e a partir de práticas desde as quais estas noções são construídas e mantidas justamente para manutenção destas relações de poder. $O$ aparato burocrático-administrativo é apenas uma parte deste sistema, dependente também de um conjunto de saberes em cuja base reside a premissa de que o único regime de conhecimento "legítimo" seja aquele produzido pelo polo hegemônico na relação de dominação; incluindo aí o manejo da subjetividade, da afetividade, da corporalidade, etc. - esse conjunto de relações se mantém, talvez até de forma mais ampliada, nos dias de hoje, obscurecendo e negando as formas de ser/estar no mundo que não se adequem a este modelo homogeneizante, sendo tidas e havidas como saberes "subalternos", senso-comum, "crenças"... Inserimos aqui, certamente, as 
formas de se relacionar com e a partir do corpo, dos afetos, da religiosidade, que caracterizam a sexualidade, nos povos indígenas, inclusive.

\section{O objetivo da colonização é libertar o colonizado de ser ele mesmo}

A colonização é, do ponto de vista da sociedade hegemônica, uma grande narrativa unilinear e teleológica não apenas de apagamento, mas de justificação para esse processo, como se o colonizador estivesse libertando o colonizado do julgo de ser si mesmo, deixando com que ele fosse, no processo, sujeito de seus próprios desejos, ações, conflitos e representações. O colonizador conta sua história como se fosse um narrador onisciente: nossa motivação foi chamar a atenção para os não ditos nessa narrativa, para os espaços em branco entre as linhas. Como já tive ocasião de afirmar ${ }^{3}$, os silenciamentos tornam-se naturalizados: mais do que se perguntar "Por que" isso ocorre talvez seja uma questão de compreender "como" isso ocorre e de que maneiras esses processos de subalternização e silenciamentos dão sentido à própria ordem colonial. No caso indígena, por exemplo, é impossível descolar essas questões da incorporação compulsória da mão de obra indígena ao sistema de exploração hegemônico. Autorxs como Fanon, Cesaire, Anzaldúa e outrxs deixam claro como esse processo de esvaziamento de si é parte fundamental do processo de colonização, de tal modo que estas questões acabam ultrapassando as fronteiras das discussões sobre indígenas para nos ensinar sobre racismo, colonialismo epistêmico, "coxinhas" e batedores de panelas, etc. Uma das bases do sistema colonial é, justamente, estruturar-se (ideológica e institucionalmente) no sentido de

\footnotetext{
${ }^{3}$ Parte desta resposta foi retirada da entrevista fornecida ao Jornal Já (RS), em 5 de junho de 2017, intitulada "Antropólogos lançam estudo sobre índios gays no Brasil" disponível em https://www.jornalja.com.br/indios-gays-no-brasilhistorias-nao-contadas-sobre-a-colonizacao-das-sexualidades-indigenas /, acessado em 29 de junho de 2017.
} 
tentar incutir, no "outro", a ideia de que a diferença é algo a ser anulado e apagado - não para a manutenção do poder desde o polo hegemônico, mas como um gesto de grandeza e gentileza para com o subalternizado.... Assim, "cura-se" o gay: não porque sua existência deixe evidente as contradições de um sistema moral heteronormado e violento, mas para "salvá-lo" do inferno. Se constroem usinas sobre terras indígenas: não porque haja conglomerados financeiros e interesses diversos de políticos, empresários, etc., mas para trazê-los ao "progresso".... "Veja bem" - dizem as instituições hegemônicas desde perspectivas científicas, religiosas, ideológicas - "você não tem culpa por ser negro, nordestino, indígena,... por professar uma religião de matriz africana, por morar na Amazônia... e, por você não ter culpa lhe ensinarei, impondo meus valores morais, religiosos, raciais, econômicos, filosóficos, epistemológicos como falar certo, agir certo, a abandonar esse "sotaque esquisito", essas roupas, essas “crenças" para se tornar o que eu sou”... é como se a única saída possível fosse se adequar ao sistema hegemônico, se enquadrar. Depois disso tudo ser imposto, cabe ao dominado entender que, por mais que ele tenha lutado - daí a importância na crença liberal da meritocracia, outra falácia na moda nos círculos conservadores - ele não conseguiu se tornar aquilo que se tentou fazer com que ele se tornasse. Daí porque lutas contra racismos, lgbtfobia, ultranacionalismos, etc. são tão importantes: elas representam mais do que a resistência a uma lógica de opressão econômica e/ou ideológica, mas a luta pelo próprio direito de res/ex-istir. A história nos mostra que por 500 anos, por exemplo, se impôs a indígenas que buscassem se transformar em brancos - e não qualquer branco: o branco subalternizado, o camponês pobre, mas cristão, monogâmico, hetero e "cidadão de bem", consumidor e bom pagador de impostos. Tudo isso para seu próprio bem... Esse apagamento das diferenças é algo perigoso, pois, a partir daí, tolhe-se o direito a existências diversas daquelas aceitas desde a lógica hegemônica... A existência desses “outros" põe em xeque as estruturas desde as quais esses dispositivos 
hegemônicos se sustentam - eis aí porque esta ânsia em se apagar estas formas outras de ser, saber, res/ex-istir.... Temos aí um ponto de toque entre noções como colonização e abjeção, e desde aí uma crítica epistemopolítica poderosa ao racismo e a heteronormatização compulsória como políticas de Estado - algo pelo qual alguns setores de nossas elites têm demonstrado um tremendo fascínio nos últimos tempos.

\section{Um dos pontos centrais do processo de colonização é a obsessão, por parte do colonizador, de se controlar todos os aspectos da cultura indígena, em especial seu corpo e sexualidade.}

Penso, como apontado anteriormente, que tais processos não atinjam somente aos indígenas, mas a diversos grupos a partir de outras dialéticas ainda que, possivelmente, da mobilização de um mesmo conjunto de dispositivos discursivos. No tocante aos indígenas, esse tipo de controle era (e é) implementado como forma de incorporá-los gradualmente a um sistema moral, econômico, estético e, especialmente, a um novo regime de subjetividade a partir do qual eles negassem a si mesmos - seja, por exemplo, pela justificativa de livrá-los do pecado ou de torná-los “civilizados”, como visto acima. Na prática, isso significa que o ato de vesti-los; de obrigá-los a ir à igreja; de formar uma família monogâmica, aos moldes da sociedade colonizadora; de adotar nomes não-indígenas, conforme regras distintas das organizações sociais indígenas; de se cortar o cabelo ou empregar práticas de gestão do corpo alheias à sua cultura, interferiram diretamente em aspectos relacionados a sexualidade, afetividade, etc. É possível, neste sentido, traçar um roteiro desde este olhar da subordinação do desejo do outro como prática colonial. Interessante notar como o aparato administrativo oficial leva(va) adiante um conjunto de práticas institucionais em cuja base reside/ia, justamente, essa subordinação. Mas não apenas a existência deste aparato e suas práticas chamam a atenção, como também as justificativas - morais, religiosas, filosóficas e científicas - utilizadas para levar adiante esse conjunto 
de ações. O que acontece e acontecia nas aldeias era, muitas vezes, repercussão de fenômenos e discussões que tomavam lugar em círculos acadêmicos e filosóficos da Europa e do Brasil sobre temas como civilização, raça e natureza, por exemplo. Um outro ponto diz respeito à incorporação dos próprios indígenas a este sistema de esvaziamento de si pela imposição de casamentos interétnicos, regimes de trabalho, divisões internas, de uma noção idealizada de indianidade. Neste sentido, não se pode descolar o preconceito sofrido por vários indígenas queer da ação de igrejas, instituições oficiais e mesmo de algumas lideranças. Isto vai ao encontro de um conjunto consolidado de narrativas a partir das quais se pode inferir, com alguma segurança, que, via de regra, esses sujeitos não sofriam preconceitos e sanções em suas aldeias até o contato interétnico.

\section{A "colonização sexual" contribuiu para a colonização geral e cultural dos povos nativos do Brasil}

A visão de que o manejo indígena de seus corpos, afetos e prazer era "contra a natureza", ou fruto de uma "raça" fadada ao fracasso ou pervertida, de certa forma, tinha uma dupla consequência. Por um lado, fornecia a justificativa para o controle ostensivo da intimidade indígena, controlando suas formas de residência e casamento, sua ontologia, suas práticas corporais, sua reprodução física, por exemplo. Por outro, trazia à tona a questão da adequação, ou não, da incorporação indígena à civilização, desde um viés racial (e racista), mesmo. Há relatos, por exemplo, em textos científicos do século passado, de que a "pederastia" poderia ser causada pela tuberculose de algum avô ou pai. A homossexualidade diz respeito não apenas à questão do manejo da intimidade indígena, ou do controle e gestão das populações (como Foucault aponta, em seu História da Sexualidade I), mas também na salvação espiritual da colônia (daí a pregnância do conceito de "sodomia"), bem como da conformação racial a um padrão moral pré-estabelecido pela metrópole. Ciência, filosofia e religião davam o instrumental retórico 
necessário para pôr o aparato colonizador em jogo, mas era na gestão cotidiana dos corpos e desejos indígenas, especialmente, que este aparato se fazia sentir.

Abrindo aqui um parêntesis, tenho plena consciência das implicações do uso do termo "homossexualidade", nos termos acima, para referir-se a esse conjunto de fenômenos. O conceito de "Homossexual" surge, como faz questão de me lembrar cada parecerista que analisou meus textos até hoje, na metade do século XIX em uma Europa burguesa e moderna. Indo mais além, mesmo entre nós essas noções não são muito bem delimitadas - basta ver a sopa de letrinhas que usamos para definir as inúmeras identidades e papéis sexuais e afetivos possíveis. Possivelmente "homodesejante" (bomodesire) resolvesse parte do problema - "parte", veja bem. Daí a opção em trabalhar com os processos de heteronormatização compulsória enquanto parte inerente ao processo colonial, seguindo aqui a inspiração de intelectuais e ativistas two-spirit.

Aliás, uma crítica dessxs indígenas à antropologia diz respeito a nós, antropólogos, buscarmos particularizar demais essas práticas ("qual o papel da sexualidade a partir das noções de pessoa na etnia x?", por exemplo). Isso acaba diluindo a preocupação, por parte delxs, de chamar a atenção para os processos de normalização característicos da colonização. Assim, mais do que a questão de nossos próprios limites heurísticos para trabalhar com o tema, há outras questões a serem levadas em conta, tais como o preconceito e o medo. Não apenas não podemos simplesmente pegar uma prancheta e marcar um "x" do lado de cada indivíduo LGBT nas aldeias (como se isso fosse possível, ou necessário), mas jamais poderíamos fazer isso sem que isso tivesse implicações no âmbito daquela comunidade, da etnia, do contato e, claro, da vida daquela pessoa. O ponto é: a quem interessaria fazer um levantamento desses? Por outro lado, há pontos obscuros que talvez devessem ser devidamente investigados, como, por exemplo, o número de suicídios, mortes e agressões ocasionados nas aldeias por conta de questões 
ligadas a sexualidade e gênero (inclusive agressões contra mulheres indígenas). Em todo o caso, penso que tais iniciativas deveriam partir, sobretudo, dxs próprixs indígenas.

Desta forma, o uso da expressão guarda, em si, um aspecto político. Gay e "homossexual" são categorias que surgem em contextos não indígenas, ocidentais e modernos. Quando um indígena é visto por outro, ou pela sociedade envolvente, como "gay", isso significa que toda a carga estigmatizante e preconceituosa do termo é também empregada. Assumi-la é enfrentá-la.

Além desta questão mais política, o termo também é usado como uma grande expressão guarda-chuva, posto que as fontes etnográficas e históricas não fazem maiores distinções entre as várias formas de sexualidade e gênero vividas pelos povos indígenas desde o início da colonização, fazendo uso de termos genéricos e repletos de juízo de valor como “sodomitas", "pederastas", "pervertidos”, ... O próprio uso de termos nativos para nominar essas práticas é algo metodologicamente discutível, posto que, ou projetará nossas visões sobre sexualidade nesses coletivos, ou impossibilitará entendermos povos nos quais esse conjunto de práticas é cotidiano sem ser, entretanto, nominada ou nominada em outros termos.

Isso dito, o que se vê é surgir, desde os anos 1970 (quando começa a se consolidar o movimento indígena de forma mais organizada no país) um discurso de que a homossexualidade equivaleria à "perda da cultura" - ou seja, o indígena LGBT seria menos indígena do que o heterossexual. Isso ainda é bem frequente e é uma das grandes causas de preconceitos e estigmatização dos indígenas homossexuais, levando não apenas a casos de agressões físicas, mas também a assassinatos e suicídios. Não gosto de fazer este tipo de generalização, mas penso que talvez hoje o preconceito se dê de forma mais ampliada do que se dava nos primeiros séculos da colonização do país, justamente por conta de um aumento no número de agentes deste 
tipo de preconceito, tais como igrejas neopentecostais, algumas lideranças, população regional.

Infelizmente, contamos com as descrições por parte do colonizador, quase sempre com os filtros morais, religiosos, civilizatórios, ainda por ser feita uma etnoarqueologia da sexualidade por parte dxs próprixs indígenas.O que se tem, para deixar claro, é um conjunto de relatos nos quais as práticas sexuais eram usadas para mostrar como aqueles indígenas, polígamos, antropófagos, nus, sodomitas, apegados ao cauim - sem fé, sem lei, sem rei precisavam ser incorporados ao sistema hegemônico, para seu próprio bem e do reino. Essa narrativa começa na colonização e persiste até os dias atuais: se no começo tal discurso era utilizado para justificar a escravidão indígena, hoje persiste para tomar, deles, seus direitos e territórios.

Racismo, LGBTfobia e colonização são termos cujos sentidos e significados mudam ao longo do tempo, mas cujas práticas permanecem, historicamente falando, com poucas mudanças estruturais: esvazia-se o outro de si mesmo, retirando dele, como dissemos anteriormente, qualquer agência histórica, qualquer subjetividade, qualquer lugar de enunciação possível fora dos termos impostos pelo colonizador.

Seja como for, de modo geral, cabe destacar aqui que a colonização das sexualidades indígenas é um conjunto de processos de longa duração, incluindo uma série de pequenas ações cotidianas articuladas entre si, de modo a normalizar a vida indígena, moldando-os ao sistema moral hegemônico. Assim, recuperando o que foi dito acima, o simples fato de um indígena se assumir como "gay" e "indígena" significa um duplo ato de resistência, tanto do ponto de vista de sua sexualidade quanto de sua etnicidade - quando se fala em "homossexualidade indígena", por mais problemático que seja do ponto de vista analítico, isso subverte uma dupla camada de preconceito. Sua própria existência é, em si, um ato de resistência. 


\section{E agora?}

O aparato estatal e religioso funciona e funcionou historicamente como um rolo compressor, no tocante a imposição do manejo moral dos povos indígenas, funcionando como força motriz da colonização das sexualidades indígenas. As propostas nas quais posso pensar, dados os limites e desafios indicados aqui, consistem em (a) formar uma rede que possa mapear essa diversidade e como a colonização repercutiu de modo mais específico sobre cada povo, desde cada agente, em cada momento histórico, utilizando determinados meios e articulando certos discursos e dispositivos; e (b) que esta rede privilegie xs próprixs indígenas, tornando possível uma interlocução mais estreita entre indígenas de diferentes etnias, idades e gêneros.

No início deste texto, chamei a atenção para como os fracassos e problemas teimam em não aparecer nos textos lindos, coerentes e bemacabados que publicamos. Até aqui, esta pesquisa teve várias intempéries, tais como: falta de ferramental analítico, preconceitos diversos, relativa falta de uma sistematização das fontes para a pesquisa e alguma resistência por parte de setores hegemônicos dentro da própria academia.

A primeira (falta de ferramental analítico) era esperada, a começar com o tipo de categorias a serem usadas e como viriam a ser utilizadas. A tentação ao anacronismo ou a projetarmos nossas perspectivas em um estudo é enorme, mas isso incorre no risco de se transformar a pesquisa em uma aplicação dos conceitos ocidentais, modernos, euronorcêntricos, em um contexto social, cultural e histórico diferente. Por outro lado, corre-se o risco de se transformar a homossexualidade indígena em algo "exótico", ou curioso. Assim, uma alternativa deixa de ser se estudar " $a$ " homossexualidade indígena para toma-la como ponto de partida para reflexões mais aprofundadas sobre as várias questões apontadas aqui, como, por exemplo, colonialismo ou heteronormatividade. A segunda dificuldade (preconceitos) 
era, também, esperada. Várias lideranças indígenas se recusam a falar sobre o tema, justamente, por haverem incorporado a ideia de que a homossexualidade seja um fenômeno externo e contraditório às tradições. Ao se conversar com algumas dessas lideranças, se nota como tal discurso se relaciona com ideias que chegam às aldeias por meio de agentes de instituições oficiais ou de igrejas, ou mesmo pela mídia, redes sociais e pelo convívio cotidiano com a sociedade envolvente. Ouvi em uma entrevista, por exemplo, de um alto funcionário do governo, que "os indígenas aprenderam a ser gays com funcionários da saúde não-índios, que levaram também drogas até as aldeias, fazendo orgias com os indígenas e daí surgindo o homossexualismo (sic)". Esse tipo de discurso é reproduzido de diversas maneiras ao se trabalhar a questão, como se a homossexualidade se transmitisse por contágio, como doença, levando à perda da identidade cultural. A terceira dificuldade (falta de sistematização das fontes) também era óbvia. Há uma vasta literatura que dava conta da existência de "índios sodomitas" nas colônias portuguesas na América desde a década de 1530. Como disse antes, o problema é que este material não traz o ponto de vista desses sujeitos, nem maiores informações sobre qual seu papel em suas culturas, estando repleto de juízos de valor. Assim, boa parte desse material servia para ilustrar como o indígena precisava ser colonizado, escravizado ou morto. Como consequência disso, são ainda raros os textos escritos pelos próprios indígenas sobre sua (homos)sexualidade. Isso nos leva à última dificuldade apontada acima (resistência de setores hegemônicos na academia): espera-se, sempre, que alguns dos cânones de estudos sobre gênero e sexualidade sejam usados em textos relativos a este campo, independente da temática. Sair disso é contrapor boa parte do senso-comum douto e a estrutura de poder da própria academia, contrapondo as clássicas divisões disciplinares e hierárquicas entre esses campos.

Temos que gostar menos de ouvir o som da nossa própria voz e olhar para o lado, para fora, para além. Nos tornamos gradualmente 
hiperespecializados em nossos próprios campos de pesquisa, o que dificulta enxergar pontos de congruência e de divergência no material disponível. Quem trabalha com gênero muitas vezes não tem tempo ou interesse para trabalhar com etnologia indígena; quem trabalha com etnologia entre os Tupi nem sempre consegue estabelecer um diálogo com os estudiosos sobre povos Jê; a discussão sobre colonialismo nos departamentos de História nem sempre alcançam os de Ciências Sociais, e por aí vai. Trabalhar com esse tipo de material implica, necessariamente, em um rompimento com as estruturas clássicas de departamentos acadêmicos com perspectivas muito específicas, de modo que se encontra, ao mesmo tempo, no âmbito da Antropologia, da Sociologia, da História, dos Estudos de Gênero, sobre Colonialismo.

O tripé racismo-sexualidade-colonialismo implica em construir pontes as quais nem sempre conseguem ser construídas, consolidadas e ampliadas, muitas vezes devido à cobrança em termos de produtividade e pesquisa, políticas de financiamento, divisões administrativas na academia, etc.

No final das contas, o que se tem é a percepção de como a colonização é um processo atual, impondo preconceitos, hierarquias, estabelecendo e mantendo um sistema de poder, invisibilizando a diversidade de formas de ser, amar, existir, resistir e conhecer. Tais questões remetem à necessidade da desconstrução de mecanismos de opressão que levam à morte e ao sofrimento de incontáveis pessoas por conta de sua raça, etnia ou sexualidade. Trata-se de se chamar a atenção para possibilidade da construção de novos paradigmas, política e historicamente situados, que permitam oferecer um contraponto ao senso comum e a narrativas científicas há muito consolidadas. 